\title{
REFLECTION
}

\section{Sharing My Diagnosis: How Much is Too Much?}

\author{
Heather A. Thompson Buum, MD \\ University of Minnesota, Minneapolis, \\ Minnesota
}

\begin{abstract}
I am a primary care physician diagnosed with breast cancer in 2016. After my diagnosis, I began to wonder, is it ever appropriate to disclose my situation, my diagnosis, any details about my cancer journey to my patients? On the one hand, physicians go to great lengths to protect privacy; on the other hand, patients appreciate the ability to share and connect, including knowing that their doctor has been through something similar. In this essay, I explore the nuances of oversharing versus making a personal connection and how the two elements of this dual role might ultimately benefit each other.
\end{abstract}

Ann Fam Med 2019;17:173-175. https://doi.org/10.1370/afm.2365.

L ately, I have been struggling with the concept of "TMI." As in, revealing too much information; being very open, having no filter, getting too personal-in particular when it comes to patients. In the literature, "physician self-disclosure" has been met with mixed results as to whether it benefits or detracts from the doctor-patient relationship. ${ }^{1}$ And, after all, isn't this the opposite of what is generally taught in medical school? That in order to maintain a professional working environment, we need boundaries; we're told not to reveal too much about ourselves. We don't want to compromise the doctor/patient relationship, or detract from the objectivity. Of course, a warm bedside manner is helpful, but otherwise, keep the cards close to the chest.

But as I consider my experience, I seem to have moved in the opposite direction. I have been a primary care physician for over 15 years; along the way, I discovered that opening up to my patients when asked, or when the timing seemed right, seemed to strengthen the doctor-patient relationship. Sharing stories about my family or my hobbies more quickly established rapport and a high level of trust than say, discussing Minnesota weather. Becoming a mom in particular changed the dynamic with my mostly female panel ${ }_{i}$ early on we would commiserate about the tough stuff—breastfeeding woes, sleepless nights, colic! — while also sharing some mutually beneficial observations.

Then, my perspective shifted even more starting in April 2016. I found a lump at home, and was diagnosed with breast cancer. I faced multiple medical decisions, this time about my own health. Afterwards, I was struck by how much more often breast cancer seemed to be showing up in my clinical practice. Sometimes I would wonder, is it simply a heightened awareness? Was I not paying this much attention until my own health issue rose up and hit me over the head? Nevertheless, I encountered many situations in which drawing upon my own experience would help the patient sitting right in front of me, and then I had to ponder-how much do I share?

Adding to this dilemma is the fact that I chose to seek care within my own health system. I swallowed my pride, suppressed any notion of privacy for myself and sought out my colleagues at the University, specifically for their expertise. I searched Google and then performed a literature search, even reading through all their papers on PubMed before deciding that the docs two floors below me in the same building were the best fit.
Heather A. Thompson Buum, MD Assistant Professor of Medicine University of Minnesota MMC 741

455 Delaware Street SE Minneapolis, MN 55455 thomp057@umn.edu 
As a result, I'm getting many internal referrals, from my surgeon, his nurse, my oncologist, her care team. If they see a patient with a new diagnosis of breast cancer who doesn't have a primary physician, or needs a pre-op, I am generally the next appointment on their list. And I welcome that. I truly enjoy this newfound synergy and expertise, relating to the fear and uncertainty immediately following a cancer diagnosis; appreciating the controversies surrounding surgical decision making such as contralateral prophylactic mastectomy; knowing in great detail the side effects of tamoxifen, having been on this drug for two years now. I can share this knowledge with my patients, help inform the discussion. It has been extremely rewarding to be able to use my experience to help others. But it's hard, at times, to decide; do I tell this patient that I am also a survivor? Or will that seem awkward, TMI?

I often try and pick up on certain cues, such as when a patient is involved in a cancer advocacy group. Or, sometimes the patients even ask me, how do you know so much about breast cancer? At times I choose to reveal this information; other times, not. But each time I have, surprisingly, my patients have responded in an extremely positive fashion. Thanking me for sharing, shaking my hand, even giving me a hug. They mention it at future visits, express gratitude for opening up to them. And for those internal referrals, I can relay the utmost confidence in their care team, because after all, I chose the same docs myself. All of this has an incredible effect on relieving tension and stress in these patients. They visibly decompress, right in the exam room; the panic in their eyes dissipates, the furrowed brow relaxes, the clenched jaw eases into a slight smile. I think about it from their perspective, if I were the patient, I would appreciate knowing my doctor has been through this too, and understands my situation. It's an expression of empathy. And it might add credibility to our recommendations, which could benefit patient outcomes. I'll say, "Just stay on Tamoxifen for a while, the hot flashes will go away. Trust me..."

Becoming a patient has also made me reconsider other areas regarding privacy, such as HIPAA. While HIPPA was designed to protect against sharing of patient information with third parties noninvolved in patient care, now it extends beyond that, creating potential barriers between doctors and their own patients. The interpretation that privacy must be preserved above all else has led to creating rules and regulations, some of course necessary, but many are obstacles to effective and efficient patient care.

After my diagnosis, I had new insights regarding patient communication. I found that this notion of calling a clinic phone number and actually getting in touch with the right person is a pipe dream, same with the black hole we call Mychart Messages. I resorted to e-mail and even text messaging my physicians to communicate more quickly and effectively. When developing a post-op complication, axillary web syndrome, I was able to text my surgeon a picture of my right arm. We arrived at the correct diagnosis and treatment plan in a matter of minutes, something that would have taken days or even weeks using traditional routes. I'm not sure if this was a "secure" way to share information, but I simply didn't care.

Come to think of it, for years I've had my e-mail address printed on my business card, and none of my patients have ever abused it. It's usually something simple, like needing a medication refill sent to a different pharmacy, or relaying a laboratory result outside our system. Or helpful, sending a quick update after a subspecialist visit is actually more informative than reading a templated note containing reams of useless data. Each time I give patients my e-mail, I warn them that it is not secure and they have to sign a waiver to this end. And guess what? They are more than happy to sign, to have a much easier exchange of information. Lately, yes, I have even allowed a few patients to text me. Not only because of my recent experience but also, my teenage son tells me nobody reads e-mail anymore.

Another aspect of TMI might relate to the design of clinic spaces. For two years, I have been practicing in the Clinics and Surgery Center, a brand-new, ultramodern, "open lobby/no front desk/collaboration zone/ touchdown space/flexible use" building. At any rate, one of the main concerns with so much open space is when reporting to clinic or laboratory or MRI others around you can hear what is being said, what appointments you have that day, and so on.

But what is interesting to me is to observe how this actually plays out. As a patient, I check in, I am given a tablet device to fill out forms, and a locator badge so that the nurses can find me. Next, I will have a seat in a vast open lobby on a floor with multiple clinics but no assigned waiting rooms. Instead, mid-century modern furniture is arranged in groupings, and floor to ceiling windows and austere marble seems to amplify and echo sound throughout the space. At times, it is a humbling experience; I will hear someone on their phone, pacing through the lobby, saying yes the biopsy is cancer, we need to do more scans, the doctors will decide on surgery.... I see patients in hats or head scarves, face mask in place, turning to other patients around them, sharing stories of the "red devil"—-doxorubicin—and the subsequent nausea and vomiting.

Outside the imaging center, I take a seat next to an older lady with short gray hair; she turns to me, and smiles, and says, "I am a breast cancer survivor, three years out! How about you?" 
To this I reply, "It's my one year cancer-versary."

"Congratulations!" she says. "Love that term!" I tell her my 10 year old daughter coined the phrase; she proceeds to show me pictures of her grandkids on her phone. Sitting across from us is a middle-aged man; he says, "Good job, you two! I'm five years out, doing great!" At which point I am reminded, men can get breast cancer, too. Same thing occurs after the mammogram, before the oncology visit. I take a seat in a different area across from a rather young-appearing couple on an orange loveseat, low coffee table between us. They turn to me and say, "Are you here to see Dr Blaes, too? We just love her!"

On and on it goes. Perfect strangers, sharing stories about their lives, their health, their latest test results, even horror stories about chemo. Supporting one another through this process, in their own unique way. The polar opposite of what hospital attorneys might have us believe; that privacy is valued at all costs, over and above what benefit there might be in sharing information, opening up to others, even in the most unlikely of situations. Perhaps the open lobby concept is not necessarily a design flaw or a way to conserve square footage, but, intentional, to encourage face-to-face interactions, and to underscore the point-we're all in this together.
These experiences and observations have served to shape my practice style; I've definitely become more open and willing to share my story with my patients. I'm still trying to navigate this concept of TMI. I have no easy answers, but I do see potential benefits. Helping patients cope with the nature of an illness, a new diagnosis, potentially frightening or confusing treatment plans - that's what I spent years of my life training to do, and continue to do, every day.

I just never thought I would accomplish any of it in quite this way.

To read or post commentaries in response to this article, see it online at http://www.AnnFamMed.org/content/17/2/173.

Key words: primary care issues; clinician-patient communication/ relationship

Submitted July 17, 2018; submitted, revised, October 17, 2018; accepted November 29, 2018.

\section{References}

1. Arroll B, Allen EC. To self-disclose or not self-disclose? A systematic review of clinical self-disclosure in primary care. Br J Gen Pract. 2015;65(638):e609-e616.

\section{Get the Annals of} Family Medicine by E-mail

SEPTEMBER/OCTOBER 2018 * Vol 16, No. 5

Editorials | Original Research | Research Briefs I Systematic Reviews I Reflections I Innovations | Departments

\section{Editorial Fellowship: Now accepting applications}

The full text of the journal is available online at hitto://www annfammed org and through various ggregators, including PubMed Central, EBSCO, and MDConsult. The Annals is indexed in the MEDLINE, Science Citation Index Expanded, Current Contents/Clinical Medicine, EMBASE, and CINHAL databases.

\section{EDITORIALS}

In This Issue: Nothing Simple Kurt C. Stange

The Long Loneliness of Primary Carey Timothy P. Daaleman

Clinical Prediction Rules: Challenges, Barriers, and Promises Emma Wallace; Michael E. Johansen

\section{ORIGINAL RESEARCH}

Social lsolation and Patient Experience in Older Adults

Takuya Aoki; Yosuke Yamamoto; Tatsuyoshi Ikenoue; Yuka Urushibara-Miyachi; Morito Kise; Yasuki Fujinuma; Shunichi Fukuhara

Social isolation is associated with a negative patient experience in older primary care patients in Japan. 